\title{
Paradigma Penelitian Manuskrip Al-Qur'an: dari Diskursus ke Metodologi
}

\author{
Achmad Yafik Mursyid \\ Program Studi Ilmu Al-Qur'an dan Tafsir, Universitas Islam Negeri Sunan Kalijaga Yogyakarta \\ Email: achmad.mursyid@uin-suka.ac.id
}

\begin{abstract}
Abstrak. Penelitian ini bertujuan untuk memahami metodologi penelitian manuskrip AlQur'an berdasarkan asumsi-asumsi dasar penelitian. Kebutuhan atas metodologi manuskrip Al-Qur'an didasarkan atas jumlah manuskrip Al-Qur'an yang banyak disimpan tidak hanya di Indonesia melainkan juga di negara lain, seperti Inggris, Belanda, Malaysia dsb. banyaknya manuskrip Al-Qur'an yang ditemukan berbanding terbalik dengan jumlah penelitian terhadap manuskrip Al-Qur'an. beberapa perguruan tinggi di Indonesia, khususnya prodi Ilmu Al-Qur'an dan Tafsir belum banyak yang memperkenalkan kajian ini kepada mahasiswanya. Hal ini disebabkan kurangnya literatur yang fokus membahas kajian manuskrip Al-Qur'an. penelitian ini menggunakan pendekatan kualitatif dengan mengumpulkan literatur-literatur yang berkaitan dengan manuskrip Al-Qur'an. hasil penelitian ini menunjukan bahwa kajian atas manuskrip Al-Qur'an telah digunakan dalam penelitian atas sejarah Al-Qur'an. hal ini terlihat pada beberapa penelitian yang dilakukan oleh para orientalis yang membahas tentang sejarah Al-Qur'an seperti Alphonso Mingana, Christoph Luxenberg, Nabia Abbot serta metodologi textual criticism criticism yang diperkenal oleh para orientalis dalam mengkaji Al-Qur'an. Penelitian ini memberi kontribusi dalam memetakan diskursus kajian manuskrip Al-Qur'an dan juga menawarkan metodologi baru dalam penelitian manuskrip Al-Qur'an.
\end{abstract}

Kata Kunci: Manuskrip Al-Qur'an, Orientalis, Diskursus, Metodologi.

\section{PENDAHULUAN}

Sejarah peradaban ilmu pengetahuan tidak bisa dilepaskan dari kontribusi kajian manuskrip. Penulisan karya ilmiah membutuhkan sumber-sumber yang otoritatif dan tidak sedikit sumber-sumber tersebut berasal naskah tulisan tangan atau (manuscript). Data-data yang terdapat pada sebuah Manuskrip memberikan informasi yang primer dalam penelitian humaniora, seperti sosiologi, antropologi, sejarah dan studi Islam². Dalam kajian sejarah misalnya sumber-sumber informasi berupa naskah yang berasal dari era klasik menjadi syarat utama keabsahan informasi sejarah. Hal ini disebabkan sumber informasi yang berupa manuskrip dianggap lebih otentik dibandingkan sumber informasi berupa tuturan atau cerita.

Pentingnya kajian manuskrip tidak serta merta menjadikan kajian ini banyak diminati oleh para peneliti di Indonesia. dibandingkan dengan ilmu-ilmu bantu lainnya seperti sejarah, hukum, filsafat dsb, kajian mannuskrip dianggap sebagai ilmu yang kurang menarik dan kuno. Hal ini bisa difahami karena kajian manuskrip tidak langsung berkaitan

\footnotetext{
${ }^{1}$ Oman Fathurahman, Filologi Indonesia : Teori Dan Metode, Cet.1 (Prenadamedia group, 2015), 15.
} 
dengan problematika kekinian, melainkan berkaitan dengan informasi yang berasal dari masa lalu. Sedikitnya peminat kajian manuskrip dapat dilihat pada jumlah guru besar yang menekuni bidang manuskrip. Hal ini bertolak belakang dengan jumlah manuskrip yang berkaitan dengan Indonesia. Konon terdapat 20.000 manuskrip yang terkait dengan Indonesia yang sekarang tersimpan di Perpustakaan Universitas Leiden, Belanda. Jumlah ini belum termasuk manuskrip yang disimpan di negara lain, sebut saja Inggris, Malaysia, Prancis, Jerman, Rusia, Afrika Selatan dan di beberapa negara lain². bahkan manuskrip yang disimpan di dalam negeri baik yang disimpan di perpustakaan, museum maupun koleksi pribadi jumlahnya sangat banyak ${ }^{3}$.

Kategori manuskrip Islam mendominasi jumlah manuskrip yang disimpan di Indonesia. hal ini disebabkan tradisi tulis-menulis sudah mapan di nusantara ketika agama Islam masuk ke nusantara ${ }^{4}$. Disamping aspek jumlah yang relatif banyak, naskah-naskah agama, khususnya Islam memiliki dampak yang penting dalam perkembangan tradisi keagamaan umat Islam di Indonesia pada era sekarang. Slogan "Islam Nusantara" yang diperkenalkan ormas NU yang mana dianggap sebagai representasi dari tradisi Islam di Indonesia memiliki akar kuat pada khazanah naskah-naskah Islam klasik ${ }^{5}$. Praktik-praktik keagamaan kita saat ini bersumber dari informasi yang didapatkan dalam manuskrip keIslaman. Manuskrip-manuskrip tersebut terdiri dari, Fikih, Tasawuf, Filsafat, Kalam, Hadis, Al-Qur'an dan lain sebagainya.

Jumlah manuskrip Islam yang relatif banyak di Indonesia termasuk juga manuskrip Al-Qur'an memberikan kita potensi informasi yang berlimpah tentang tradisi Islam di Indonesia. Manuskrip-manuskrip Al-Qur'an di Indonesia memberikan informasi kepada kita tentang sejarah Islam di Indonesia. Hal ini dikarenakan Al-Qur'an tidak bisa dilepaskan dari tradisi masyarakat Muslim. Sejarah Al-Qur'an secara otomatis mengambarkan sejarah umat Islamnya. Akan tetapi, minimnya kajian tentang manuskrip Al-Qur'an di Indonesia, menjadikan informasi tentang sejarah Islam menjadi kurang otentik. Menurut data sejarah, Islam di Indonesia sudah ada sejak abad ke $13 \mathrm{M}^{6}$, akan tetapi penelitian terhadap khazanah manuskrip Al-Qur'an tertua yang ditemukan tertanggal abad $17 \mathrm{M}^{7}$. Terdapat jarak yang cukup lama antara sejarah Islam dengan sejarah Al-Qur'an di Indonesia, oleh sebab itu. Penelitian-penelitian terkait dengan kajian manuskrip Al-Qur'an perlu menjadi prioritas bagi kalangan pengkaji Al-Qur'an.

Kajian manuskrip Al-Qur'an bukanlah diskursus baru dikalangan peneliti Islam. Para sarjana Barat mengawali kajian tentang Islam melalui manuskrip-manuskrip Al-Qur'an, sebut saja tokoh-tokoh seperti Theodore Noldeke, Ignaz Goldziher, Alphonso Mingana, Christoph Luxenberg, Nabia Abbot dsb. hal ini berbeda dengan tradisi kajian Islam di kalangan sarjana Muslim yang cenderung menggunakan riwayat sebagai sumber informasi. Hal ini terlihat pada kitab-kitab Ulum Qur'an dan Tarikh Qur'an seperti Tarikh Qur'an karya

\footnotetext{
${ }^{2}$ Henri Chambert, Khazanah Naskah : Panduan Koleksi Naskah-Naskah Indonesia Se Dunia, ed. Trans. Oman Fathurrahman (Yayasan Obor Indonesia, 1999), 27.

${ }^{3}$ Fathurahman, Filologi Indonesia: Teori Dan Metode, 17.

${ }^{4}$ Tim Peneliti balai Litbang Agama Jakarta, Naskah-Naskah Taubid Di Indonesia Bagian Barat (Jakarta: Balai Penelitian dan pengembangan Agama Jakarta, 2013), 5. 32.

5 Ahmad Baso, Islam Nusantara: Ijtihad Jenius \& Ijma' Ulama Indonesia (Pamulang: Pustaka Afid, 2015),

${ }^{6}$ Ibn Batutta, The Travel of Ibnu Battuta (Mineola: Dover Publications, 2004), 617.

${ }^{7}$ Ali Akbar, "Pencetakan Mushaf Al-Qur'an Di Indonesia," SUHUF, 2011.
} 
Abu Abdillah Az-Zanjani (w. 1941) ${ }^{8}$, 'Ulum al-Qur'an karya Manna' al-Qattan (w. 1999) ${ }^{9}$ serta Tarikh Al-Qur'an karya Abdul Shabur Syahin (w. 2010) ${ }^{10}$. Ketiga kitab tersebut memberikan penjelasan tentang sejarah Al-Qur'an dari tradisi riwayat. Bahkan kitab Mabahist fi 'Ulum Al-Qur'an karya Subhi Shalih (w. 1986) ${ }^{11}$ yang dianggap sebagai kitab 'Ulum Al-Qur'an kontemporer hanya menjelaskan sepotong informasi tentang sejarah AlQur'an dan tidak didasarkan kepada informasi dari khazanah manuskrip Al-Qur'an.

Berdasarkan problematika dan urgensi kajian manuskrip Al-Qur'an, maka penelitian ini ditujukan untuk menawarkan tradisi baru dalam kajian Al-Qur'an. Kajian manuskrip AlQur'an hendaknya menjadi alat bagi para pengkaji Al-Qur'an untuk mendapatkan sumbersumber otoritatif terkait dengan Al-Qur'an. penelitian ini mencoba memberikan tawaran metodologis dalam mengkaji manuskrip Al-Qur'an.

\section{METODE PENELITIAN}

Penelitian tentang diskursus dan metodologi manuskrip Al-Qur'an dipilih dalam penelitian ini berdasarkan pada tren peningkatan dalam penelitian terhadap naskah-naskah klasik, khususnya Al-Qur'an. Peningkatan dalam penelitian naskah-naskah Al-Qur'an berdampak pada kebutuhan atas rumusan metodologi baru yang akomodatif terhadap penelitian naskah Al-Qur'an. penelusuran atas metodologi manuskrip Al-Qur'an dilakukan dengan memanfaatkan literatur-literatur terkait dengan kajian manuskrip Al-Qur'an dan juga manuskrip Islam secara umum. Hasil penelusuran tersebut dijadikan sebagai data primer dalam penelitian ini. Untuk mendukung data yang dihasilkan dari data primer, penelitian ini juga menggunakan data sekunder yang berasal dari berbagai literatur terdahulu yang memiliki relevansi dengan tema penelitian.

Penelitian ini menggunakan metode content analysis (analisis isi) dengan jenis penelitian kualitatif. Dengan menggunakan metode analisis isi, peneliti dapat membuat kesimpulan yang valid dari data yang diperoleh. ${ }^{12}$ Dalam proses pengolahan data, penelitian ini menggunakan tiga tahap, yakni perencanaan, pelaksanaan dan display. Tahap perencanaan dilakukan dengan menyusun variabel-variabel penelitian yang dibutuhkan untuk mempermudah pencarian data. Variabel yang telah disusun disesuaikan dengan keberadaan data untuk dilakukan klasifikasi yang dilanjutkan dengan menampilkan data sebagai bagian dari data utama.

\section{PERDEBATAN TENTANG OTENTISITAS AL-QUR'AN MELALUI MANUSKRIP AL-QUR'AN}

Awal mula kajian manuskrip al-Qur'an muncul lebih disebabkan adanya polemik terkait dengan otentisitas Al-Qur'an. sebagian sarjana meyakini bahwa naskah Al-Qur'an tidak ditulis pada awal kemunculan Islam. bagi kelompok ini Al-Qur'an dianggap tidak otentik karena tidak ditemukan bukti-bukti naskah Al-Qur'an yang ditulis pada masa-masa

\footnotetext{
8 Abu Abdullah Az-Zanjani, Wawasan Baru Tarikh Al-Qur'an, ed. Terj. Kamaludin Marzuki Anwar (Bandung: Mizan, 1986).

${ }^{9}$ Manna` Qattan, Mababith Fi 'ulum Al-Qur'an (Bayrut: Mu'assasat al-Risalah, 2009).

${ }^{10}$ Abdul Shabur Syahin, Tarikh Al-Qur'an (Kairo: Nahdhah Mishr, 2005).

${ }^{11}$ Subhi As-Shalih, Membahas Ilmu-Ilmu Hadis (Surakarta: Pustaka firdaus, 1997).

12 Marilyn Domas White and Emily E. Marsh, "Content Analysis: A Flexible Methodology," Library Trends 55, no. 1 (2006): 23, https://doi.org/10.1353/lib.2006.0053.
} 
awal Islam ${ }^{13}$. di sisi lain, sebagian sarjana lain meyakini bahwa keberadaan Al-Qur'an telah ada ketika masa-masa awal Islam ${ }^{14}$. Para sarjana tersebut menemukan bukti-bukti naskah bahwa Al-Qur'an ditulis dan diproduksi di awal Hijriah. Polemik terkait otentisitas AlQur'an tersebut lebih banyak dikaji oleh sarjana-sarjana Barat, seperti Alphonse Mingana, Christoph Luxenberg, Nabia Abbot dsb. Adapun kesimpulan-kesimpulan yang dihasilkan dari kedua kelompok ini, sama-sama bersumber dari kajian naskah-naskah klasik. Hal ini tidak mengherankan karena kajian naskah lebih mendapat perhatian dari para sarjana Barat.

Sarjana barat yang cukup vokal dalam meyakini bahwa Al-Qur'an tidak otentik adalah Alphonse Mingana dan Christoph Luxenberg. Mereka mengklaim bahwa sumbersumber Arab terkait dengan Al-Qur'an tidak cukup otoritatif dalam menjelaskan sejarah AlQur'an. Al-Qur'an bagi mereka hanya kumpulan cerita-cerita yang diambil dari tradisi Yahudi-Nasrani di era itu. Mingana dalam bukunya yang berjudul An Ancient Syriac Translation of the Kur'an exbibiting New Verses and Variants memberikan penjelasan bahwa kosakata dalam Al-Qur'an berasal dari bahasa Syiriac. Mingana menemukan bukti kemiripan dalam naskah-naskah bahasa Syiriac yang cocok dengan bahasa Al-Qur'an. bukti-bukti tersebut mengarahkan Mingana pada kesimpulan bahwa tradisi Al-Qur'an bersumber dari tradisi bahasa Syiriac bukan dari tradisi bahasa Arab ${ }^{15}$.

Pendapat serupa juga dikembangkan oleh Christoph Luxenberg. Luxenberg dalam bukunya Syro-aramaic reading of the koran : a contribution to the decoding of the language of the koran, Ia mengklaim bahwa asal usul bahasa Arab adalah bahasa Syirio-Aramaic. ${ }^{16}$ Hal ini mendorong asumsi Luxenberg bahwa, dalam memahami Al-Qur'an diharuskan merujuk pada komunitas-komunitas Aram dan kristen yang berbahasa Syirio-Aramaic. Bahkan Luxenberg berasumsi bahwa Makkah bukan merupakan pemukiman Arab, melainkan pemukinan bangsa Aram yang berbahasa Aramaic. Asumsi-asumsi dasar Luxenberg yang terkait dengan bahasa Syirio-Aramaic menuntun dia dalam melakukan penelitian berbasis naskah-naskah Al-Qur'an dengan mengunakan metode linguistik. Dia mengklaim bahwa dokumen-dokumen Arab klasik termasuk Al-Qur'an menggunakan Bahasa Syirio-Aramaic. Hal ini dikarenakan, karaktek teks naskah-naskah tersebut tidak memiliki tanda diakritik dan vokal, sehingga memungkinkan untuk Luxenberg memasukan naskah tersebut dalam bahasa selain Arab ${ }^{17}$.

Klaim-klaim yang diajukan oleh Mingana dan Luxenberg mendapatkan kritikan dari para pengkaji Manuskrip Al-Qur'an lainnya, termasuk Nabia Abbot. Kritikan ini terkait dengan asal-usul bahasa Arab yang disandarkan pada bahasa Syirio-Aramaic. Abbot dalam bukunya The Rise of The North Arabic Script And Its Kur'anic Development, With A Full Description of The Kur'an Manuscripts In The Oriental Institute membantah klaim Mingana bahwa

\footnotetext{
${ }^{13}$ Alphonse Mingana, An Ancient Syriac Translation of the Kur'ān, Exbibiting New Verses and Variants (Manchester: University Press, 1925).

${ }^{14}$ Nabia Abbot, “The Rise of the North Arabic Script and Its Kur'ānic Development, with a Full Description of the Kur'ān Manuscrípts in the Oriental Institute. By Nabia Abbott. (University of Chicago Oriental Institute Publications, Volume L.) Pp. Xxii, 103, Pis. 33. Univ," Bulletin of the School of Oriental and African Studies, 1940, https://doi.org/10.1017/s0041977x00088790.

${ }^{15}$ Mingana, An Ancient Syriac Translation of the Kur'ān, Exbibiting New Verses and Variants.

${ }^{16}$ Christoph Luxenberg, Syro-Aramaic Reading of the Koran: A Contribution to the Decoding of the Language of the Koran. (Berlin: H. Schiler, 2007), 277.

${ }^{17}$ Luxenberg, 306.
} 
bahasa Arab sudah ada pada awal abad hijriah ${ }^{18}$. Abbot membuktikan klaim tersebut dengan menghadirkan bukti manuskrip berbahasa Arab tertanggal $22 \mathrm{H}$ yang ditemukan di Mesir. Manuskrip ini menunjukan bahwa tradisi bahasa Arab sudah banyak dikenal masyarakat Arab. Hal ini terlihat pada penulisan huruf Arab yang akurat pada manuskrip tersebut. Klaim ini membantah argumentasi Mingana bahwa bahasa Arab tidak dikenal pada masyakarakat Arab di Makkah dan Madina.

Abbot selanjutnya berargumen bahwa asal-usul bahasa Arab lebih dekat dengan bahasa Nabatean dibandingkan dengan bahasa Syirio-Aramaic ${ }^{19}$. Pendapat ini mendapat konfirmasi dari peneliti Paleografi Arab, Grohmann dan J. Healey. Healey dalam artikel yang diterbitkan di Manuscripts of the Middle East: Journal devoted to the study of handwritten materials of the Middle East, Vol. 5, 1991 berjudul "Nabataean to Arabic: Calligraphy and Script Development Among The Pre-Islamic Arabs" mengklaim bahwa asal-usul aksara Arab adalah aksara Nabatean ${ }^{20}$. Pendapat ini kemudian dijadikan dasar oleh Muhammad Mustafa Al-Azami dalam bukunya The History of the Quranic Text, from Revelation to Compilation: A Comparative Study with the Old and New Testaments dalam menjelaskan sejarah aksara Al-Qur'an yang berasal dari aksara Nabatean ${ }^{21}$.

\section{MANUSKRIP AL-QUR'AN SEBAGAI DISKURSUS PENELITIAN BERBASIS NASKAH.}

Polemik terkait otentisitas teks Al-Qur'an menjadi pemicu munculnya kajian-kajian manuskrip Al-Qur'an lainnya. Para peneliti setelahnya lebih banyak memiliki variasi dalam model penelitian terhadap manuskrip Al-Qur'an. Kajian mereka tidak hanya berhenti pada penjelasan otentisitas Al-Qur'an saja, melainkan juga menekankan kepada unsur-unsur pembentuk Al-Qur'an seperti variasi rasm, iluminasi, Qiraa'at kaligrafi serta penanggalan manuskrip Al-Qur'an yang ditemukan. Para peneliti tersebut adalah Tayyar Altikullac, François Déroche, David James, Alba Fadeli, Yasin Dutton, Annabel T Gallop, Islah Gusmian dan juga Ali Akbar. Disamping itu, terdapat corak baru dalam penelitian manuskrip Al-Qur'an yang lebih menekankan kepada fenomena resepsi masyarakat terhadap manuskrip Al-Qur'an. kajian ini mulai di minati oleh para pemerhati Living AlQur'an. Adapun berdasarkan penanggalan, kajian manuskrip Al-Qur'an dapat dikategorisasikan menjadi 2 masa: Manuskrip Al-Qur'an era awal Islam (Early Qur'anic Manuscript) dan Manuskrip Al-Qur'an lokal (Magribi Qur'anic Manuscript, Iranian Qur'anic Manuscript, Ottoman Qur'anic Manuscript dsb.)

Tayyar Altikullac dalam beberapa bukunya, fokus dalam melakukan penelitian terhadap Manuskrip-Manuskrip Al-Qur'an yang disandarkan kepada Mushaf Usmani. Manuskrip-manuskrip tersebut disimpan di beberapa tempat yang berbeda, antara lain Taskent, Topkapi Museum Turki, Mashhad Imam Husaini Kairo, San'a dan juga Museum di Tubingen dan Paris. Meskipun banyak kalangan yang mengklaim bahwa manuskripmanuskrip tersebut disandarkan kepada Mushaf Usmani, akan tetapi secara filologis, data-

\footnotetext{
${ }^{18}$ Nabia Abbot, The Rise Of The North Arabic Script And Its Kur'anic Development, With A Full Description Of The Kur'an Manuscripts In The Oriental Institute (Chicago: University of Chicago Press, 1939), 46.

19 Abbot, 9.

${ }^{20}$ J F Healey, "Nabataean to Arabic: Calligraphy and Script Development Among the Pre-Islamic Arabs," Manuscripts of the Middle East 5 (1991): 45.

${ }^{21}$ Muhammad Mustafa Al-A'zami, The History of Quranic Text From Revelation to Compilation, UK Islamic Academy, 2003, 135.
} 
data yang dihimpun menurut Tayyar berasal dari paruh kedua abad $1 \mathrm{H}$ dan paruh pertama abad ke $2 \mathrm{H}$ atau pada masa kekuasaan Umayyah (661-750 M). Tayyar berkesimpulan bahwa, manuskrip-manuskrip tersebut merupakan salinan dari mushaf-mushaf yang dikirim oleh Khalifah Usman ke beberapa kota ketika terjadi kodifikasi Al-Qur'an ${ }^{22}$.

Adapun Déroche fokus dalam melakukan kajian terhadap manuskrip-manuskrip yang teridentifikasi ditulis pada era Umayyah dan Abbasiyah. Déroche membuat catatancatatan kritis terkait dengan karakteristik mushaf Al-Qur'an era Umayyah dan perkembangannya di era Abbasiyah. Francois Deroche membandingkan sejumlah mushaf dari berbagai koleksi, seperti di Prancis, Inggris, Mesir, dan sebagainya, kemudian mengidentifikasi huruf, tanda baca, gaya tulisan, dan seterusnya. Kemudian dia merekonstruksi sedemikian rupa sehingga sampai pada kesimpulan adanya gaya tertentu pada masa kekhalifahan Umayyah. Déroche menemukan ada 4 gaya dalam penulisan huruf Hijaz yang mana hal tersebut menunjukan karakter dari masa yang berbeda ${ }^{23}$.

David James dalam bukunya The Master Scribes: Qur'ans of the $10^{\text {th }}-14^{\text {th }}$ Centuries $A D$ melakukan katalogisasi manuskrip Al-Qur'an yang teridentifikasi berasal dari abad 10-14 M. Dalam bukunya David James membagi pembahasan menjadi 2 bab antara lain manuskrip Al-Qur'an yang berasal dari abad 10-13 dan bab kedua dari abad 13-14. Pembagian ini berdasarkan karakteristik manuskrip Al-Qur'an yang ditemukan. James berkesimpulan bahwa pada abad 10-13 kegiatan penulisan Al-Qur'an mengalami perkembangan yang cukup signifikan baik dari aspek penulisan maupun materialnya. Perkembangan ini menunjukan adanya perhatian yang signifikan dari para pemimpin, sehingga pada abad 1314 muncul lebih banyak varian mushaf yang teridentifikasi memiliki gaya penulisan yang indah dan menggunakan material yang mewah. Hal ini bisa dilihat pada manuskrip AlQur'an yang berasal dari magribi. Manuskrip Al-Qur'an magribi memiliki gaya penulisan yang khas, yang oleh James disebut Western Kufic. Pada aspek material pada abad ini mushaf ditulis dengan kertas yang berbentuk landscape, berbeda dari masa sebelumnya yang cenderung portrait ${ }^{4}$.

Kajian manuskrip Al-Qur'an di era sekarang semakin dikenal secara luas. Hal ini terlihat pada beberapa kegiatan yang diselenggarakan oleh IQSA International Qur'anic Studies Association), salah satunya adalah Annual Meeting yang diadakan sejak tahun 2013. Setiap penyelengaraan Annual Meeting terdapat sub-tema tentang manuskrip Al-Qur'an. adapun Annual Meeting tahun 2020 diselenggarakan secara virtual dan pada sub-tema The Qur'an: Manuscript and Textual Criticism, Peneliti Manuskrip Al-Qur'an Alba Fedeli menjadi koordinator pada tema tersebut. Alba Fedeli merupakan ahli Manuskrip Al-Qur'an yang sekarang bekerja sebagai dosen di Universitat Hamburg. Fokus kajian Fedeli adalah manuskrip Al-Qur'an yang terindikasi berasal dari abad 7 M. Fedeli dalam disertasinya yang dipublikasikan di University of Birmingham pada tahun 2015 dengan judul Early Qur'anic manuscripts, their text, and the Alphonse Mingana papers held in the Department of Special Collections of the University of Birmingham, menggunakan metode Digital Philology dalam meneliti transmisi

\footnotetext{
${ }^{22}$ Tayyar Altıkulac, Al-Musșaf Al-Sharif: Attributet to 'Uthmān Bin 'Affān (The Copy at the Topkapı Palace Museum) (Istanbul: Research Center for Islamic History, Art and Culture, 2007).

${ }^{23}$ Franc,ois Déroche, Qur'ans of the Umayyads : A First Overview (Leiden: Brill Academic Publishers, 2014).

${ }^{24}$ David James, The Master Scribes : Qur'ans of the 10th to 14th Centuries AD (London: The Nour Foundation, 1992).
} 
manuskrip tersebut. metode ini merupakan sebuah terobosan baru dalam kajian manuskrip Al-Qur'an sejak semakin banyaknya project digitalisasi manuskrip Al-Qur'an ${ }^{25}$.

Penelitian terhadap manuskrip Al-Qur'an tidak hanya mendeskripsikan umur atau penanggalan sebuah manuskrip saja, melainkan juga isi yang terkandung di dalamnya. Peneliti yang memfokuskan pada ranah kajian ini salah satunya adalah Yasin Dutton. Yasin Dutton tercatat pernah mengajar di University of Oxford dan University of Edinburgh. Sekarang dia merupakan Professor Emeritus di University of Cape Town pada bidang Bahasa dan Sastra Arab. Dutton dalam artikelnya berjudul An Early Mushaf according to the reading of Ibn 'Amir mengidentifikasi Qira'at yang digunakan pada manuskrip Al-Qur'an abad 1 (Arabe 328a) yang disimpan di Bibliothèque Nationale, Paris. Dutton memastikan bahwa struktur bacaan pada manuskrip tersebut teridentifikasi memiliki kemiripan dengan Qira'at Ibn 'Amir'. Dutton dalam artikel lain yang berjudul Red Dots, Green Dots, Yellow Dots \& Blue: Some Reflections on The Vocalisation of Early Qur'anic Manuscripts mengidentifikasi beberapa unsur pembentuk Al-Qur'an yang terdapat pada manuskrip abad 3 dan 4 H yang disimpan di Bodleian Library (Oxford). Dutton mendeskripsikan beberapa variasi Qira'at Shadh yang ditandai dengan perbedaan warna. Warna-warna pada manuskrip tersebut seperti merah, hijau, kuning dan biru menjadi penanda pilihan Qira'at ${ }^{7}$. Penelitian yang serupa juga dilakukan oleh peneliti yang lain termasuk diantara adalah Alain George $e^{28}$.

Kajian manuskrip Al-Qur'an di Indonesia belum mendapatkan perhatian yang maksimal dari para peneliti. hal ini terlihat dari banyaknya manuskrip yang belum terkatalogisasikan dengan baik $^{29}$. Adapun beberap peneliti yang fokus pada kajian manuskrip Al-Qur'an di Indonesia adalah Annabel T Gallop, Ali Akbar dan Islah Gusmian. Annabel $^{30}$ merupakan kepala koleksi manuskrip asia tenggara di British Library. Adapun Ali Akbar $^{31}$ merupakan peneliti di Bayt Al-Qur'an dan Museum Istiqlal yang fokus kajiannya adalah manuskrip Al-Qur'an nusantara, sedangkan Islah Gusmian ${ }^{32}$ adalah peneliti sekaligus dosen di IAIN Surakarta, beliau adalah kolektor naskah-naskah Al-Qur'an dan tafsir di

${ }^{25}$ Alba Fedeli, “Early Qur'ānic Manuscripts, Their Text, and the Alphonse Mingana Papers Held in the Department of Special Collections of the University of Birmingham" (University of Birmingham, 2015).

${ }^{26}$ Yasin Dutton, "An Early Muṣhaf According to the Reading of Ibn CĀmir,"

Http:/ / Dx.Doi.Org/ 10.3366/Jqs.2001.3.1.71 3, no. 1 (August 30, 2010): 71-89, https://doi.org/10.3366/JQS.2001.3.1.71.

${ }^{27}$ Yasin Dutton, "Red Dots, Green Dots, Yellow Dots and Blue: Some Reflections on the Vocalisation of Early Qur'anic Manuscripts - Part I," Journal of Qur'anic Studies 1, no. 1 (April 1999): 11540, https://doi.org/10.3366/JQS.1999.1.1.115; Yasin Dutton, "Red Dots, Green Dots, Yellow Dots and Blue: Some Reflections on the Vocalisation of Early Qur'anic Manuscripts (Part II)," Journal of Qur'anic Studies 2, no. 1 (January 2000): 1-24, https://doi.org/10.3366/JQS.2000.2.1.1.

${ }^{28}$ Alain George, "Coloured Dots and the Question of Regional Origins in Early Qurans (Part I)," Journal of Qur'anic Studies 17, no. 1 (February 1, 2015): 1-44, https://doi.org/10.3366/JQS.2015.0178.

${ }^{29}$ Tim Peneliti balai Litbang Agama Jakarta, Naskah-Naskah Taubid Di Indonesia Bagian Barat.

${ }^{30}$ Annabel Teh Gallop, “The Appreciation and Study of Qur'an Manuscripts from Southeast Asia: Past, Present, and Future," Heritage of Nusantara: International Journal of Religious Literature and Heritage (eJournal), 2016, https://doi.org/10.31291/HN.V4I2.84.

31 Ali Akbar, "Pencetakan Mushaf Al-Qur'an Di Indonesia," n.d.; Annabel Teh Gallop and Ali Akbar, "The Art of the Qur'an in Banten: Calligraphy and Illumination," Archipel 72, no. 1 (2006): 95156, https://doi.org/10.3406/arch.2006.4028.

32 Islah Gusmian, Khazanah Tafsir Indonesia, Dari Hermeneutika Hingga Ideologi (Jakarta: Teraju, 2003); Islah Gusmian, "Bahasa Dan Aksara Tafsir Al-Qur'an Di Indonesia Dari Tradisi, Hierarki Hingga Kepentingan Pembaca," TSAQAFAH, 2010, https://doi.org/10.21111/tsaqafah.v6i1.136; Islah Gusmian, "Tafsir Al-Qur'an Di Indonesia: Sejarah Dan Dinamika," Nun : Jurnal Studi Alquran Dan Tafsir Di Nusantara, vol. 1, December 29, 2015, https://doi.org/10.32459/NUN.V1I1.8. 
nusantara. Annabel, Ali Akbar dan Islah, ketiganya memberikan kontribusi terhadap kekayaan khazanah manuskrip Al-Qur'an di Indonesia. Database tentang manuskrip AlQur'an di Indonesia menjadi studi pendahuluan bagi para pengkaji manuskrip Al-Qur'an nusantara.

Perkembangan kajian manuskrip tidak hanya berhenti pada analisa kritik teks (textual criticism) saja melainkan juga bisa dijadikan objek kajian dalam penelitian sosialhumaniora. Manuskrip Al-Qur'an dianggap sebagai objek material yang saling terkait dengan kehidupan manusia. Penelitian-penelitian tentang ini lazim kita sebut sebagai Living Mushaf. Beberapa peneliti yang sudah memulai penelitian dengan menggunakan analisa ini adalah Natalia K. Suit dalam artikel yang berjudul Mushaf and The Material Boundaries of The Qur'ān ${ }^{33}$. Eva Nugraha ${ }^{34}$ dalam artikel berjudul Saat Muṣhaf al-Qur'än Menjadi Komoditas, begitu juga Endy Saputra ${ }^{35}$ dengan artikel berjudul Mushaf 2.0 dan Studi Al-Qur'an di Era "Muslim Tanpa Masjï".

\section{CARA PANDANG MANUSKRIP AL-QUR'AN SEBAGAI OBJEK PENELITIAN}

Posisi manuskrip al-Qur'an abad pertengahan oleh banyak kalangan dianggap memiliki otoritas selayaknya al-Qur'an. Mereka mengaggap tidak diperlukan pengkajian atas manuskrip-manuskrip tersebut karena kesalahan terhadapanya tidak memungkinkan terjadi. Hal ini disebabkan, al-Qur'an dimulai dengan tradisi oral yang tersimpan dalam hafalan umat muslim dari generasi ke generasi, sehingga tranformasi ke dalam bentuk tulisan dianggap terjaga. Dengan sedikitnya kajian atas teks-teks tertulis tersebut, banyak peneliti barat justru mengambil alih penelitian tersebut dalam rangka menjawab kegelisahan akademik mereka mengenai struktur al-Qur'an yang tertulis.

Tranformasi dari budaya lisan menjadi tulis, menjadikan persoalan yang berkaitan dengan salinan al-Qur'an pasca kodifikasi menjadi perhatian utama kalangan sarjanawan barat. Al-Qur'an yang bertranformasi dari budaya lisan menjadi budaya tulis, kemudian bertranformasi dari budaya tulis menuju kodifikasi, dan dari kodifikasi kemudian menjadi naskah yang disalin, menjadi pintu masuk dikalangan sarjanawan untuk menjadikannya sebagai salah satu objek penelitian, paling tidak dalam wilayah filologis.

Eldon Epp $^{36}$ memberikan struktur mendasar dalam proses peralihan ini: pertama, Prodecessor Text form, yakni sumber lisan maupun tulisan yang digunakan oleh penulis. Dalam kaitannya dengan al-Qur'an, yang dimaksudkan dengan teks pendahulu adalah teks yang berasal dari rasul, baik berupa hafalan (lisan) maupun tulisan para penulis wahyu yang telah dikonfirmasi oleh Nabi. Kedua, Autographic text-form, yakni salinan dari teks-teks sumber asli. Ketiga, Authoritative text-form, yakni teks yang telah memperoleh kesepakatan dalam satu kawasan geografis. Dalam konteks ini, maka yang dirujuk adalah manuskrip awal al-Qur'an yang telah dikodifikasi dan disepakati oleh para ulama (Kodifikasi awal al-Qur'an, mushaf Ali, Ibn Mas'ud, dll). keempat, Canonical text-form, yakni teks yang memperoleh kesepakatan

\footnotetext{
${ }^{33}$ Natalia K Suit, "Mushaf and The Material Boundaries of The Qur'ān," in Iconic Books and Texts, ed. James Watts (Equinox Publishing, 2013).

${ }^{34}$ Eva Nugraha, “Saat Muṣhaf Al-Qur’ān Menjadi Komoditas,” Refleksi, 2014, https://doi.org/10.15408/ref.v13i6.998.

${ }^{35}$ Muhammad Endy Saputro, "Mushaf 2.0 Dan Studi Al-Qur'an Di Era 'Muslim Tanpa Masjid,” MIQOT: Jurnal Ilmu-Ilmu Keislaman, 2019, https://doi.org/10.30821/miqot.v42i2.502.

${ }^{36}$ Eldon Jay Epp, “The Multivalence of the Term 'Original Text' in New Testament Textual Criticism," The Harvard Theological Review 92, no. 3 (1999): 245-81.
} 
secara meluas. Misalnya mushaf uthmani. Kelima, Interpretive text-form, yakni penyalinan teks yang dilakukan setelahnya dengan beberapa perbaikan gaya tulisan, model penulisan, dan tradisi penulisan dalam sebuah tempat (dogmatik).

Dalam wilayah interpretative text-form, al-Qur'an mengalami beragam variasi dari segi penulisan yang disesuaikan dengan kebutuhan tiap masa. Meskipun pada masa outhografi juga memungkinkan adanya perubahan semacam ini, karena terdapat penyalinan dari teks asli yang dilakukan oleh para sahabat. Misalnya dalam penggunakan lambang bacaan yang panjang. Bacaan panjang dalam beberapa manuskrip menggunakan kata alif, ya' dan waw. Misalnya beberapa manuskrip menggunakan alif dan manuskrip yang tidak menggunakan alif (ابرهيم - ارهم / (فال-قل). Adanya kekeliruan dalam penyalinan. Hal ini dapat dilihat dalam

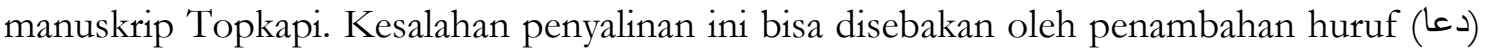
ditulis (الادعا), adanya kesalahan penulisan disebabkan oleh kata yang mirip (غير) ditulis

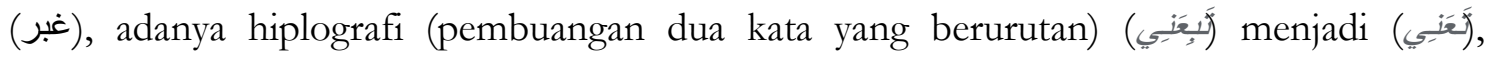
kesalahan dalam diakritik (tanda haruf yang ditunjukkan dengan titik), yakni antara qaf dan $f a$ '. Dan selain itu juga dipengaruhi oleh varian rasm.

\section{a.Hermeneutika Teks Al-Qur'an}

Analisa Hermeneutika terhadap teks dalam manuskrip Al-Qur'an selalu diartikan dengan upaya menemukan bentuk asli dari teks dengan melakukan pembandingan atas teks yang berubah dikarenakan upaya penyalinan. Hal demikian disebabkan karena teks adalah diskursus tertulis yang selalu melibatkan dialektika antara peristiwa dan arti dan dialektika arti dan referensi. Jika manuskrip Al-Qur'an dianggap sebagai peristiwa, maka ia adalah rangkaian teks yang telah usang, karena beralihnya waktu. Akan tetapi, jika ia dianggap memuat teks yang memiliki makna, maka diskursus yang terkandung di dalamnya akan bertahan di dalam isi proposisionalnya. Arti adalah objek ideal yang dimaksudkan oleh proposisi, sehingga ia berada di dalam (immanent) diskursus. Dengan sifatnya yang immanent di dalam diskursus, maka arti menunjukkan sisi objektivitas sebuah teks. Selain itu, arti akan selalu menunjukkan pada sisi referensialnya, yakni menjelaskan "tentang apa"nya sebuah teks. Referensi selalu menunjukkan pada nilai kebenaran dari proposisi yang tuntutannya menjangkau kenyataan, sehingga ia selalu bersifat subjektif. ${ }^{37}$

Dalam keadaan semacam ini, hermeneutika menemukan tujuannya dalam teks yang terdapat pada manuskrip Al-Qur'an. Meskipun penulisan manuskrip telah berjarak berbagai generasi dari masa hidup si pencipta, teks senantiasa menawarkan kemungkinankemungkinan baru untuk menerangkan situasi-situasi yang berbeda dari situasi-situasi yang diinginkan penulisnya. Tawaran yang diberikan oleh teks kemudian ditangkap dengan pemahaman hermeneutikal dengan memperlihatkan dunia yang ditunjuk oleh teks melalui komposisi, genre, dan style teks. ${ }^{38}$ Hal ini dapat dilihat pada komposisi manuskrip AlQur'an yang memungkinkan terjadinya keragaman Rasm, Qira'at dan tanda Waqf. Keragaman ini menunjukan situasi yang dialami penulis pada satu sisi, dan menunjukan kemungkinan situasi lain jika diterapkan pada waktu yang berbeda.

Hermeneutika dapat digunakan sebagai alat interpretasi pada setiap teks manuskrip Al-Qur'an. Ia memuat aturan-aturan yang dapat mengungkapkan makna atas segala jenis

\footnotetext{
${ }^{37}$ Paul Ricoeur, Interpretation Theory (Fort Worth: Texas Christian University Press, 1977), 25-26.

${ }^{38}$ Ricoeur, Interpretation Theory.
} 
teks. Tugas utamanya adalah mencari dinamika internal yang mengatur struktural kerja di dalam teks di satu sisi dan mencari daya yang dimiliki kerja teks untuk memproyeksikan diri ke luar dan memungkinkan refensialnya muncul ke permukaan. ${ }^{39}$ Teks adalah diskursus yang termuat dalam tulisan. ${ }^{40}$ Diskursus mengacu pada bahasa sebagai peristiwa yang membicarakan sesuatu yang berfungsi sebagai alat komunikasi. Manuskrip al-Qur'an sebagai ekspresi kehidupan yang ditentukan secara linguistik, ${ }^{41}$ menjadi objek interpretasi hermeneutika.

\section{b. Living Manuskrip}

Manuskrip Al-Qur'an tidak hanya berfungsi sebagai dokumen sejarah yang digunakan untuk mempermudah masyarakat dalam membaca Al-Qur'an saja, melainkan mampu berperan dalam pembentukan peradaban manusia. Dalam sejarahnya, Al-Qur'an disalin dengan berbagai bentuk dan inovasi untuk menyesuaikan dan memenuhi kebutuhan pembaca. Kemunculan varian mushaf tersebut mengindikasikan bahwa mushaf turut serta dalam memproses terwujudnya identitas budaya. Setelah Islam berkembang dan tersebar keberbagai penjuru wilayah, Mushaf disalin dan disebarkan dengan berbagai macam variasi dan inovasi. Sebut saja Mushaf Sancak di Turki yaitu mushaf berukuran kecil, Mushaf Magribi di Maroko yaitu mushaf dengan kategori kaligrafi yang berbeda dengan mushaf yang berkembang, Mushaf Bombay dari India, mushaf ini pelopor penulisan Al-Qur'an dengan tradisi Imla'i, dan Mushaf Pojok dari Indonesia yaitu mushaf dengan tradisi penulisan akhir baris ditandai dengan selesainya ayat, serta Kanjeng Kyai Al-Qur'an dari Kraton Yogyakarta yaitu dengan tradisi illuminasi Islam Jawa. Inovasi dan variasi bentuk mushaf tersebut adalah wujud dari interaksi antara budaya lokal dengan penerimaan masyarakat Muslim terhadap Al-Qur'an.

Penelitian Living Manuscript mengasumsikan bahwa manuskrip bagian dari budaya material. Mushaf dilihat sebagai bentuk materi fisik yang memiliki hubungan dengan tradisi manusia. Webb Keane memberikan penjelasan singkat tentang teori Material Culture, bahwasanya teori ini merumuskan hubungan manusia dan hal-hal bersifat materi dengan mengacu pada konsep yang lebih luas terutama hubungan antara subjek dan objek. ${ }^{42}$ Penelitian Living Manuscript ingin membuktikan bahwa Mushaf tidak hanya difahami sebagai alat bantu dalam membaca Al-Qur'an saja melainkan Mushaf merupakan representasi dan identitas dari tradisi dan peradaban manusia.

\section{FILOLOGI DAN ILMU BANTU PENELITIAN MANUSKRIP AL-QUR'AN}

\section{a) Kodikologi}

Kadikologi adalah kajian mengenai sejarah naskah, sejarah koleksi naskah, tempat penyalinan dan penulisan naskah (skriptorium), tempat penyimpanan naskah, penyusunan

\footnotetext{
${ }^{39}$ E. Sumaryono, Hermeneutik: Sebuah Metode Filsafat (Yogyakarta: Kanisius, 1999), 105.

${ }^{40}$ Paul Ricoeur, "What Is a Text? Explanation and Understanding," in The Theory of Interpretation, ed. and trans. John B. Thompson (Cambridge: Cambridge University Press, 2016), 107-26, https://doi.org/10.1017/cbo9781316534984.008.

${ }^{41}$ Josef Bleicher, Contemporary Hermeneutics, Hermeneutics as Method, Philosophy and Critique (London: Routledge and Kegan Paul, 1980), 347.

42 Webb Keane, Handbook of Material Culture (London: Sage Publications, 2006), 19.
} 
katalog, perdagangan naskah dan penggunaan naskah. ${ }^{43}$ Atau singkatnya kodikologi ini adalah ilmu bantu dalam filologi untuk mengetahui fisik manuskrip Al-Qur'an. Atau dapat pula diambil kesimpulan sederhana—meski ini tidak mewakili definisi kodikologi secara menyeluruh-bahwa kodikologi pada hakikatnya adalah ilmu yang mencoba menguak dan memberikan interpretasi terhadap proses pembuatan buku yang orisinal di masa klasik, yang saat itu masih merupakan bagian dari kerajinan tangan. ${ }^{44}$

Tidak semua naskah merupakan codex. Yang disebut sebagai naskah codex dan masuk dalam penelitian ilmu kodikologi adalah manuskrip yang berbentuk lembaranlembaran berhalaman sebagaimana bentuknya buku saat ini. Sedangkan, naskah klasik atau manuskrip yang berbentuk gulungan-baik itu gulungan ke samping (volumen) atau pun gulungan memanjang (rotulus) - dan serpihan-serpihan tersendiri (single sheet) atau juga batangan-batangan kayu yang dikaitkan (accordion-fold book), tidak bisa dikatakan sebagai codex sehingga bukan termasuk objek penelitian ilmu kodikologi.

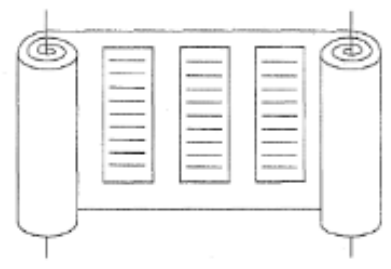

Volumen

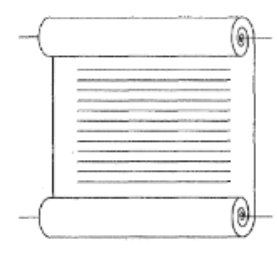

Rotulus

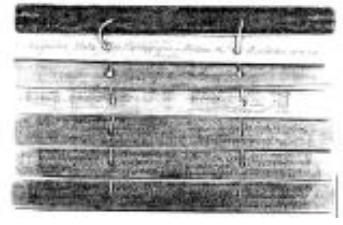

accordion-fold book



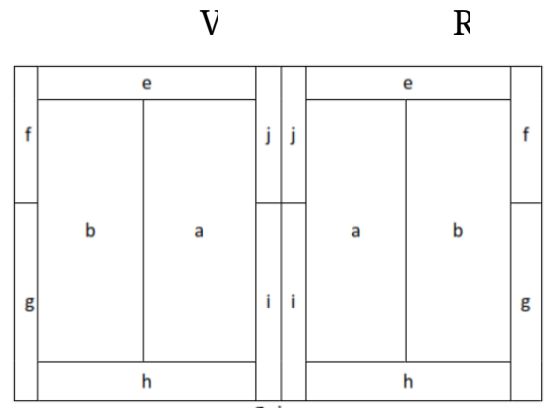

S
Ket:

Verso: Sisi belakang buku

Recto: Sisi kanan buku Spine: Sisi tengah buku

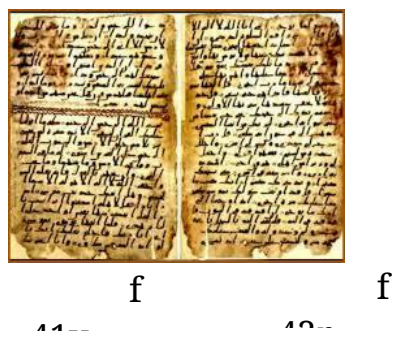

Tujuan dari ilmu kodikologi adalah menganalisa sebuah manuskrip jenis codex agar diketahui dengan jelas bagaimana teknik pembuatan manuskrip tersebut dan kapan ia dibuat. Setelah jelas semua unsur-unsur yang dikaji dalam ilmu kodikologi mulai dari teknik pembuatannya hingga jenis tintanya, tentu saja peneliti akan mudah menyimpulkan kapan sebuah manuskrip itu diproduksi. Dari analisa seorang yang ahli dalam ilmu kodikologi, sebuah naskah codex dapat diketahui kapan dibuatnya hanya dengan melihat jenis tinta dan page setting-nya. Pada masa-masa tertentu warna tinta menjadi penanda sebuah budaya.

43 Titik Pudjiastuti, "Kajian Kodikologis Atas Surat Sultan Kanoman, Cirebon (COD. OR. 2241 ILLB 17 (No. 80))," Wacana, Journal of the Humanities of Indonesia 9, no. 1 (April 2007): 12, https://doi.org/10.17510/wjhi.v9i1.222.

${ }^{44}$ Adam Bacek, Arabic Manuscript: A V ademecum for Readers (Belanda: Brill, 2009), 64. 
Menurut Francois Déroche umat Islam di masa lalu seringkali membedakan teks penting dengan warna tinta yang berbeda, misalnya merah. Tetapi, ini tidak berlaku bagi semua wilayah kekuasaan Islam. Menurut Francois Déroche yang biasa menggunakan tinta merah di awal atau akhir surah adalah manuskrip Al-Qur'an yang berasal dari Damaskus pada masa Dinasti Umayyah. Dari analisa Francois Déroche kemudian menentukan pada abad berapa mushaf tersebut dibuat. ${ }^{45}$

Termasuk bagian dari kodikologi dalam kajian manuskrip Al-Qur'an adalah Iluminasi. Iluminasi merupakan bagian dari karya seni yang bertujuan untuk memperindah buku dengan menggunakan beragam ornament baik dalam bentuk geometris, menggunakan emas dan pewarna yang diletakkan di bagian depan dan belakan sebuah buku atau di bagian tepi setiap halaman. ${ }^{46}$ Iluminasi tidak hanya berfungsi sebagai hiasan tetapi juga menunjukkan ciri-ciri kedaerahan tempat naskah-naskah itu berasal dan merupakan tandatanda yang bermakna. Illuminasi selalu berkaitan dengan keadaan dan tradisi yang melingkupi pembuat illuminasi (illuminator). Ia menentukan segala bentuk tradisi, sehingga dapat dijadikan acuan dalam menentukan masa sebuah naskah. ${ }^{47}$

\section{b) Kritik Teks}

Kritik Teks (Textual Criticism) adalah ilmu yang mempelajari hal yang berkaitan dengan teks secara mendalam termasuk di dalamnya mengenai penjelmaan dan penurunan teks, penafsiran dan pemahamannya. ${ }^{48}$ Teks adalah kandungan atau isi naskah. Teks terdiri atas isi dan bentuk. Isi mengandung ide-ide atau pesan yang ingin disampaikan oleh pengarang kepada pembaca. Sedangkan bentuk berisi muatan cerita atau pelajaran yang hendak dibaca dan dipelajari dengan menggunakan berbagai pendekatan melalui alur, perwatakan, gaya, dan sebagainya. ${ }^{49}$ Adapun langkah-langkah kritik teks dalam kajian manuskrip Al-Qur'an.

1. Menentukan sejarah teks Al-Qur'an dengan cara menganalisa Rasm, Qira'at, Waqf, Kaligrafi.

2. Secara metodis perubahan/kesalahan yang diadakan secara sadar dalam sebuah teks (perubahan Rasm, Qira'at, Waqf dll) harus didahulukan daripada perubahan/mekanis mekanis, misalnya kekeliruan tidak sadar oleh seorang penyalin

3. Teks Al-Qur'an harus diteliti sebagai keseluruhan

4. Bahan-bahan yang mengiringi sebuah teks dalam naskah Al-Qur'an harus diikutsertakan dalam penelitian seperti tanda penyambung ayat dsb.

5. Perlu diteliti pemantulan sejarah teks Al-Qur'an dalam teks-teks dan lain

6. Pekerjaan seorang penyalin dan kegiatan skriptoria-skriptoria (sanggar penulisan atau penyalinan Al-Qur'an) tertentu harus diteliti secara menyeluruh.

Hal yang paling penting dalam kajian teks adalah mengenai perubahan atau kesalahan yang terjadi dalam proses penyalinan Al-Qur'an. ${ }^{50}$ Dalam konteks penelitian

\footnotetext{
${ }^{45}$ Déroche, Qur'ans of the Umayyads: A First Overview.

${ }^{46}$ David Diringer, The Illuminated Book: Its Histori and Production (London: Faber \& Faber, 1967).

${ }^{47}$ Chalida Nuraulia Aisyanarni, "Iluminasi Naskah Melayu Karya M.Bakir Koleksi PNRI: Tinjauan Semiotica Umberto Eco” (Universitas Gajah Mada, 2013), 5.

${ }^{48}$ Elis Suryani, Filologi (Bogor: Ghalia Indonesia, 2012), 49.

${ }^{49}$ Nabilah Lubis, Naskah, Teks, Dan Metode Penelitian Filologi (Jakarta: Forum Kajian Bahasa dan Sastra Arab, Fakultas Adab IAIN Syarif Hidayatullah, 1996), 27.

${ }^{50}$ Ibid., 58.
} 
manuskrip al-Qur'an dan tafsir, langkah yang dapat diambil untuk menguraikan kritik teks adalah dengan menunjukkan jenis Rasm, Qiraat dan Kaligrafi Al-Qur'an. Adapun Rasm dan Qiraat Al-Qur'an merupakan instrumen yang akan selalu ada pada manuskrip AlQur'an. oleh sebab itu identifikasi Rasm dan Qira'at Al-Qur'an merupakan langkah awal untuk mengetahui tradisi dan asal usul manuskrip Al-Qur'an tersebut. Rasm dan Qira'aat Al-Qur'an menjadi pembeda bagi para pengkaji manuskrip pada umumnya, karena kedua hal ini hanya ditemukan pada manuskrip Al-Qur'an. kemampuan teoritis atas Rasm dan Qira'aat Al-Qur'an menjadi kualifikasi wajib bagi para pengkaji naskah Al-Qur'an.

\section{c) Paleografi}

Paleografi adalah ilmu yang mempelajari tentang berbagai tulisan kuno di atas batu, logam atau bahan lain. Paleografi mempuyai tujuan utama menjabarkan tulisan kuno karena beberapa tulisan kuno sangat sulit dibaca. ${ }^{51}$ Disamping itu, juga bertujuan menempatkan berbagai peninggalan tertulis dalam rangka perkembangan umum sebuah tulisan sehingga dapat ditentukan waktu dan tempat setiap bentuk tulisan dari aksara yang digunakan. Karena biasanya karya sastra tidak menyebutkan kapan dan dimana suatu karya di tulis, serta siapa pengarangnya. Semula paleografi digunakan untuk membaca tulisan kuno yang terdapat dalam prasasti, namun pada saat sekarang juga digunakan untuk membaca tulisan kuno yang ada dalam naskah. Perlu pula diperhatikan ciri-ciri lain, seperti interpungsi, panjang dan jarak baris-baris, bahan naskah, ukuran, tinta, dan sebagainya. ${ }^{52}$

Sebagai contoh penerapan paleografi dalam kajian manuskrip Al-Qur'an adalah penggunaan huruf yang digunakan pada manuskrip Al-Qur'an di masa awal Islam. Beberapa peneliti manuskrip Al-Qur'an seperti Déroche dan Noseda mengkategorisasikan bentuk tulisan Al-Qur'an menjadi 2 bentuk huruf. Pertama, huruf Hijaz, kedua, dan huruf Kufi. Déroche menggunakan paleografi dalam mengidentifikasi bentuk huruf yang dipakai pada manuskrip Al-Qur'an abad 1-2. Ia menyimpulkan bahwa ada empat variasi huruf pada manuskrip tersebut yaitu, Hijaz I, Hijaz II, Hijaz III, Hijaz. IV. Dalam bukunya yang berjudul The Abbasid Tradition: Qur'ans of the $8^{\text {th }}$ to the $10^{\text {th }}$ Centuries $A D$ ia menjelaskan bahwa huruf bijaz digunakan pada penulisan Al-Qur'an di abad 1 hingga abad ke 2. Penggunaan huruf hijaz tidak lagi dipergunakan pada penulisan Al-Qur'an setelahnya karena huruf kufi dijadikan sebagai huruf resmi di era akhir Umayyah, khususnya pada masa kepemimpinan 'Abd Malik bin Marwan ${ }^{53}$.

\section{d) Radio Karbon}

Radio Karbon adalah teknik penanggalan atau penentuan usia sebuah artefak arkeologi tertentu yang terbuat dari dari unsur-unsur biologis. ${ }^{54}$ Teknik ini mampu memprediksikan usia artefak sampai 50.000 tahun. Secara sederhana. Teknik radio karbon adalah teknik kimia yang menggunakan unsur karbon pada makhluk hidup untuk ditentukan usia benda tersebut. Teknik radio karbon dikembangkan oleh W.F. Libby, E.C. Anderson dan J.R. Arnold pada tahun 1949. Setelah penemuan teknik ini, sebuah

${ }^{51} \mathrm{~J} \mathrm{G}$ de Casparis, Indonesian Palaeography: A History of Writing in Indonesia from the Beginnings to C.A.D. 1500 (Leiden: Brill Academic Publishers, 1975), 24.

${ }^{52} \mathrm{~J}$ G de Casparis, 33.

${ }^{53}$ Francois Deroche, The Abbasid Tradition: Qur'ans of the 8 th to the 10th Centuries AD (London: Nour Foundation in association with Azmimuth and Oxford University Press, 1992).

${ }^{54}$ R.E. Taylor, Radiocarbon Dating An Archaeological Perspective (Orlando: Acedemic Press, 1987). 
penentuan usia artefak tidak lagi menjadi hal yang komplek dan sangat memudahkan bagi para arkeolog. Oleh sebab itu, pada tahun 1960, Libby dianugrahi penghargaaan Nobel dalam bidang kimia karena kontribusinya dalam penemuan teknik radio karbon ${ }^{55}$.

Radio karbon juga bisa diterapkan pada manuskrip Al-Qur'an. sebuah proyek bernama Corpus Curanicum, yaitu proyek yang diinisiali oleh peneliti Al-Qur'an berasal dari Jerman, Angelika Neuwirth juga menerapkan teknik radio karbon sebagai salah satu metode alternatif dalam menentukan usia manuskrip Al-Qur'an ${ }^{56}$. Corpus Curanicum menggunakan radio karbon untuk melengkapi metode tradisional dalam meneliti manuskrip Al-Qur'an dengan metode ilmiah modern. Metode filologi tradisional dianggap perlu untuk dilengkapi dengan metode ilmiah modern karena meminimalisir kesalahan. Kasus ini pernah terjadi pada penelitian yang dilakukan oleh Déroche. Ia merevisi hasil penelitiannya setelah mendapatkan informasi alternatif dari radio karbon.

\section{ALUR PENELITIAN MANUSKRIP AL-QUR'AN}

Alur Penelitian Manuskrip Al-Qur'an dapat menggunakan perangkat keilmuan filologi yang di jelaskan oleh Oman Fathurrahman ${ }^{57}$. Menurutnya, secara kronologis, alur dalam penelitian filologi adalah;

a. Menentukan Teks

Tahap paling awal dan menentukan dalam sebuah studi manuskrip adalah memilih dan menentukan teks apa yang akan dikaji. Dalam hal ini, setiap peneliti memiliki preferensi yang berbeda-beda terkait teks apa yang menurutnya menarik. Sangat mungkin bahwa teks yang dianggap menarik oleh seseorang, akan dianggap biasa-biasa saja dimata orang lain, atau mungkin sebaliknya, karena pada dasarnya setiap teks memiliki sejarah dan konteksnya tersendiri, tergantung bagaimana kapasitas dan kemampuan sang peneliti dalam memaknai teks. Karena itulah latar belakang dan perspektif keilmuan seseorang menjadi salah satu faktor penting yang akan menuntutnya dalam memilih sebuah teks untuk dikaji.

Meskipun demikian, pilihan atas teks harus diuji melalui tiga aspek; pertama, potensi korpus. Tahap ini benar-benar subjektif dan mengandalkan intuisi sang peneliti sendiri. Korpus Al-Qur'an adalah sekumpulan teks yang berisi ayat-ayat Al-Qur'an sebagai sumber penelitian dari kajian filologi. Kedua, metode dan pendekatan. Penting diketahui bahwa dalam sebuah penelitian filologi, setidaknya ada dua tugas utama yang perlu dilakukan, yakni membuat suntingan teks, melakukan analisa dan kontekstualisasi teks. Dalam penelitian manuskrip Al-Qur'an kemampuan mengidentifikasi bentuk-bentuk Rasm dan Qiraat Al-Qur'an sangat dibutuhkan dalam mengidentifikasi asal-usul naskah. Setelah identifikasi naskah sudh diketahui maka dilanjutkan dengan kontekstualisasi yang sangat memungkinkan berkolaborasi dengan disiplin ilmu yang lain, seperti sosiologi, antropologi dll. Ketiga, mengetahui konteks apa yang akan dijadikan sebagai latar analisa teks. Setiap teks dilahirkan dalam sebuah konteks yang dipengaruhi oleh zamannya, pengarangnya, dan mungkin teks lain di sekitarnya.

b.Inventarisasi Naskah

\footnotetext{
${ }_{55}^{5}$ R.E. Taylor, 170.

${ }^{56}$ GÖZELER Esra; MARX, “Corpus Coranicum Projesi: Kur’an’1 Geç Antik Döneme Ait Bir Metin Olarak Okumak,” Ankara Üniversitesi İlahiyat Fakültesi Dergisi 53, no. 2 (August 1, 2012): 219-53, https://doi.org/10.1501/ilhfak_0000001373.

${ }^{57}$ Fathurahman, Filologi Indonesia: Teori Dan Metode.
} 
Inventarisasi naskah dimaksudkan sebagai upaya cermat dan maksimal untuk menelusuri dan mencatat keberadaan naskah yang memuat salinan dari teks yang akan dikaji. Beberapa cara dapat dilakukan untuk menelusuri naskah yang memuat salinan dari teks yang sudah dipilih, antara lain dengan menggunakan katalog naskah, buku-buku yang mengupas naskah terkait, artikel-artikel jurnal, publikasi dan karya tulis.

c.Deskripsi Naskah

Deskripsi naskah Al-Qur'an dilakukan dengan melakukan identifikasi, baik terhadap kondisi fisik naskah, isi teks, rasm, qira'at, tanda waqf, kolofon maupun identitas kepengarangan dan kepenyalinannya dengan tujuan untuk menghasilkan sebuah deskripsi naskah dan teks secara utuh..

d.Perbandingan Naskah dan Teks

Tahap ini adalah melakukan perbandingan, baik naskah maupun teks dengan naskah dan teks lainnya. Dengan cara membandingkan umur kertas, jenis teks yang digunakan, ejaan, variasi bacaan dan lainnya. Hal ini dilakukan jika naskah yang ditemukan lebih dari satu dengan jenis yang sama.

\section{e.Suntingan Teks}

Suntingan teks dilakukan untuk mengubah bentuk tulisan tangan asli dengan tulisan yang dapat dibaca oleh banyak kalangan. Terdapat beberapa model dalam suntingan teks, yakni melakukan duplikasi atas teks dengan membiarkan teks apa adanya, melakukan penyalinan dengan menambahkan diakritik (tanda baca) tanpa mengubah bentuk asli tulisan, menggabungkan beberapa teks dalam satu salinan baru, melakukan penyalinan dengan mengahadirkan kritik teks yang memungkinkan teks mendapat bentuknya yang terbaik sehingga dapat lebih mudah dibaca. Pada tahapan ini bersifat opsional. Suntingan sangat perlu dilakukan jika naskah Al-Qur'an ditulis dengan menggunakan aksara selain Arab.

\section{f. Terjemahan Teks}

Terjemahan teks dilakukan jika dalam naskah Al-Qur'an terdapat keterangan yang menggunakan bahasa asing ataupun bahasa daerah. Hal ini perlu dilakukan agar kandungan dari teks bisa dipahami oleh banyak kalangan pembaca. Dalam konteks ini, kemampuan peneliti dalam memahami bahasa asal dibutuhkan untuk menyampaikan kandungan makna teks dapat efisien dan tepat.

g.Analisis Isi

Analisis isi adalah langkah terakhir dalam kajian filologi untuk menentukan kandungan teks dengan melakukan telah atas teks dan konteks sesuai dengan perspektif yang digunakan.

Analisa kandungan teks dengan menggunakan kerangka historis dan wacana yang mengelilingi teks tidak pernah menjadi pembahasan kajian filologis hingga abad ke-18. Masuknya analisa hermeneutika dalam kajian filologi modern, ataupun sebaliknya, berkaitan erat dengan perkembangan kajian teks yang mengarahkan pembahasannya pada kritik historis. ${ }^{58}$ Analisa historis dalam kajian hermeneutika bibel dipandang dapat dijadikan metode baru bagi kajian teks pada naskah-naskah lainnya di luar kitab suci. ${ }^{59}$

\footnotetext{
${ }^{58}$ Richard E. Palmer, Hermeneutika: Teori Baru Mengenai Interpretasi, trans. Musnur Hery and Damanhuri Muhammad (Yogyakarta: Pustaka Pelajar, 2005), 43.

${ }^{59}$ Frederic W. Farrar, The History of Interpretation (Whitefish: Literary Licensing, 2014), 402.
} 
Dalam konteks manuskrip Al-Qur'an, filologi tidak dapat dibedakan dengan hermeneutika kitab suci. Penelitian manuskrip Al-Qur'an berusaha mengungkap maksud dan tujuan penulisan naskah Al-Qur'an. Akan tetapi, kesamaan keduanya hanya merujuk pada definisi hermeneutika yang tidak mengalami modifikasi secara metodis. Bahkan, pada permulaan abad ke-19, hermeneutika menjelma sebagai kaidah-kaidah umum dari penafsiran filologi pada masa Schleimacher, Freidrich August Wolf dan Friedrich Ast. Schleimacher juga memiliki sumbangsih untuk meletakkan pondasi awal hermeneutika sebagai ilmu yang mendiskripsikan kondisi-kondisi pemahaman dalam semua dialog, sehingga kritik teks dalam filologi dilepaskan dengan hermeneutika. Prinsip-prinsip hemerneutika umum (allgemeine hermenetika) dapat dijadikan prinsip bagi setiap interpretasi teks di luar kajian filologi. ${ }^{60}$

\section{KESIMPULAN}

Perkembangan tradisi tulis dalam sejarah Al-Qur'an telah melahirkan warisan intelektual yang sangat kaya berupa manuskrip Al-Qur'an dan Tafsir. Warisan tersebut sangat berharga tidak hanya bagi kalangan pengkaji Al-Qur'an saja, melainkan bagi umat muslim pada umumnya. Manuskrip Al-Qur'an menyimpan beragam informasi, meliputi sejarah, agama, hukum adat dsb. data-data yang tersimpan pada koleksi naskah atau manuskrip Al-Qur'an dapat digunakan oleh para ahli dari berbagai bidang. Akan tetapi warisan intelektual tersebut tidak banyak diakses oleh para peneliti karena terbatasnya data yang terkompilasi melalui studi filologi. Oleh sebab itu, penelitian filologi pada manuskrip Al-Qur'an dan Tafsir harusnya menjadi prioritas kajian dalam diskursus Al-Qur'an.

Penelitian ini memberikan perspektif baru dalam melihat kajian manuskrip AlQur'an. dengan menggunakan kerangka teori yang diarahkan pada pembacaan karya manuskrip Al-Qur'an pada 2 wilayah. 1. Pembacaan secara diakronik penelitian-penelitian yang membahas manuskrip Al-Qur'an serta, 2. Pembacaan teoritis kajian naskah yang berkembang dalam diskursus penelitian filologi, tulisan ini memberikan tawaran teoritis dalam penelitian manuskrip Al-Qur'an dan Tafsir. Dari semua itu, kajian ini ingin menunjukan bahwa penelitian terkait sejarah Al-Qur'an bukannya sesuatu yang sakral yang tidak menerima kritik, melainkan sangat terbuka untuk dikritisi dan diperbaharui melalui kajian-kajian selanjutnya. Dalam konteks inilah pentingnya penggunaan kajian filologi dalam menganalisa sejarah Al-Qur'an. hal ini untuk menunjukan bukti-bukti otentik tentang sejarah Al-Qur'an.

\section{REFERENSI}

Abbot, Nabia. The Rise Of The North Arabic Script And Its Kur'anic Development, With A Full Description Of The Kur'an Manuscripts In The Oriental Institute. Chicago: University of Chicago Press, 1939.

Abdul Shabur Syahin. Tarikh Al-Qur'an. Kairo: Nahdhah Mishr, 2005.

Abu Abdullah Az-Zanjani. Wawasan Baru Tarikh Al-Qur'an. Edited by Terj. Kamaludin Marzuki Anwar. Bandung: Mizan, 1986.

Aisyanarni, Chalida Nuraulia. "Iluminasi Naskah Melayu Karya M.Bakir Koleksi PNRI:

${ }^{60}$ Palmer, Hermeneutika: Teori Baru Mengenai Interpretasi. 
Tinjauan Semiotica Umberto Eco.” Universitas Gajah Mada, 2013.

Akbar, Ali. "Pencetakan Mushaf Al-Qur'an Di Indonesia," n.d.

_. "Pencetakan Mushaf Al-Qur'an Di Indonesia." SUHUF, 2011.

Al-A'zami, Muhammad Mustafa. The History of Quranic Text From Revelation to Compilation. UK Islamic Academy, 2003.

Altıkulac, Tayyar. Al-Musshaf Al-Sharif: Attributet to 'Uthmän Bin 'Affan (The Copy at the Topkapı Palace Museum). Istanbul: Research Center for Islamic History, Art and Culture, 2007.

As-Shalih, Subhi. Membahas Ilmu-Ilmu Hadis. Surakarta: Pustaka firdaus, 1997.

Bacek, Adam. Arabic Manuscript: A V ademecum for Readers. Belanda: Brill, 2009.

Baried, Siti Baroroh, Sulistin Sutrisni, siti Chamamah Soeratno, and Kun Zachrun Istanti. Pengantar Teori Filologi. Yogyakarta: Badan Penelitian dan Publikasi Fakultas (BPPF), 1994.

Baso, Ahmad. Islam Nusantara: Ijtihad Jenius \& Ijma' Ulama Indonesia. Pamulang: Pustaka Afid, 2015.

Bleicher, Josef. Contemporary Hermeneutics, Hermeneutics as Method, Pbilosophy and Critique. London: Routledge and Kegan Paul, 1980.

Chambert, Henri. Khazanah Naskah: Panduan Koleksi Naskah-Naskah Indonesia Se Dunia. Edited by Trans. Oman Fathurrahman. Yayasan Obor Indonesia, 1999.

Déroche, Francois. The Abbasid Tradition: Qur'ans of the 8th to the 10th Centuries AD. London: Nour Foundation in association with Azmimuth and Oxford University Press, 1992.

Déroche, François. Qur'ans of the Umayyads: A First Overview. Leiden: Brill Academic Publishers, 2014.

Diringer, David. The Illuminated Book: Its Histori and Production. London: Faber \& Faber, 1967.

Dutton, Yasin. "An Early Muṣhaf According to the Reading of Ibn CĀmir." Http://Dx.Doi.Org/10.3366/Jqs.2001.3.1.71 3, no. 1 (August 30, 2010): 71-89. https://doi.org/10.3366/JQS.2001.3.1.71.

—. "Red Dots, Green Dots, Yellow Dots and Blue: Some Reflections on the Vocalisation of Early Qur'anic Manuscripts - Part I." Journal of Qur'anic Studies 1, no. 1 (April 1999): 115-40. https://doi.org/10.3366/JQS.1999.1.1.115.

_. "Red Dots, Green Dots, Yellow Dots and Blue: Some Reflections on the Vocalisation of Early Qur'anic Manuscripts (Part II)." Journal of Qur'anic Studies 2, no. 1 (January 2000): 1-24. https://doi.org/10.3366/JQS.2000.2.1.1.

Epp, Eldon Jay. “The Multivalence of the Term 'Original Text' in New Testament Textual Criticism.” The Harvard Theological Review 92, no. 3 (1999): 245-81.

Esra; MARX, GÖZELER. “Corpus Coranicum Projesi: Kur'an’1 Geç Antik Döneme Ait 
Bir Metin Olarak Okumak." Ankara Üniversitesi İlabiyat Fakültesi Dergisi 53, no. 2 (August 1, 2012): 219-53. https://doi.org/10.1501/ilhfak_0000001373.

Farrar, Frederic W. The History of Interpretation. Whitefish: Literary Licensing, 2014.

Fathurahman, Oman. Filologi Indonesia : Teori Dan Metode. Cet.1. Prenadamedia group, 2015.

Fedeli, Alba. "Early Qur'ānic Manuscripts, Their Text, and the Alphonse Mingana Papers Held in the Department of Special Collections of the University of Birmingham." University of Birmingham, 2015.

Gallop, Annabel Teh. "The Appreciation and Study of Qur'an Manuscripts from Southeast Asia: Past, Present, and Future." Heritage of Nusantara: International Journal of Religious Literature and Heritage (e-Journal), 2016. https://doi.org/10.31291/HN.V4I2.84.

George, Alain. "Coloured Dots and the Question of Regional Origins in Early Qurans (Part I)." Journal of Qur'anic Studies 17, no. 1 (February 1, 2015): 1-44. https://doi.org/10.3366/JQS.2015.0178.

Gusmian, Islah. "Bahasa Dan Aksara Tafsir Al-Qur'an Di Indonesia Dari Tradisi, Hierarki Hingga Kepentingan Pembaca." TSAQAFAH, 2010. https://doi.org/10.21111/tsaqafah.v6i1.136.

—. Khazanah Tafsir Indonesia, Dari Hermeneutika Hingga Ideologi. Jakarta: Teraju, 2003.

_. "Tafsir Al-Qur'an Di Indonesia: Sejarah Dan Dinamika." Nun : Jurnal Studi Alquran Dan Tafsir Di Nusantara. Vol. 1, December 29, 2015. https://doi.org/10.32459/NUN.V1I1.8.

Healey, J F. "Nabataean to Arabic: Calligraphy and Script Development Among the PreIslamic Arabs." Manuscripts of the Middle East 5 (1991): 41-52.

Ibn Batutta. The Travel of Ibnu Battuta. Mineola: Dover Publications, 2004.

$\mathrm{J} G$ de Casparis. Indonesian Palaeography: A History of Writing in Indonesia from the Beginnings to C.A.D. 1500. Leiden: Brill Academic Publishers, 1975.

James, David. The Master Scribes: Qur'ans of the 10th to 14th Centuries AD. London: The Nour Foundation, 1992.

Keane, Webb. Handbook of Material Culture. London: Sage Publications, 2006.

Lubis, Nabilah. Naskah, Teks, Dan Metode Penelitian Filologi. Jakarta: Forum Kajian Bahasa dan Sastra Arab, Fakultas Adab IAIN Syarif Hidayatullah, 1996.

Luxenberg, Christoph. Syro-Aramaic Reading of the Koran: A Contribution to the Decoding of the Language of the Koran. Berlin: H. Schiler, 2007.

Mingana, Alphonse. An Ancient Syriac Translation of the Kur'ä, Exbibiting New Verses and V ariants. Manchester: University Press, 1925.

Nabia Abbot. “The Rise of the North Arabic Script and Its Kur'ānic Development, with a Full Description of the Kur'ān Manuscrípts in the Oriental Institute. By Nabia Abbott. (University of Chicago Oriental Institute Publications, Volume L.) Pp. Xxii, 103, Pis. 33. Univ." Bulletin of the School of Oriental and African Studies, 1940. 
https://doi.org/10.1017/s0041977x00088790.

Nugraha, Eva. "Saat Muṣhaf Al-Qur'ān Menjadi Komoditas.” Refleksi, 2014. https://doi.org/10.15408/ref.v13i6.998.

Palmer, Richard E. Hermeneutika: Teori Baru Mengenai Interpretasi. Translated by Musnur Hery and Damanhuri Muhammad. Yogyakarta: Pustaka Pelajar, 2005.

Pudjiastuti, Titik. "Kajian Kodikologis Atas Surat Sultan Kanoman, Cirebon (COD. OR. 2241 ILLB 17 (No. 80))." Wacana, Journal of the Humanities of Indonesia 9, no. 1 (April 2007): 51. https://doi.org/10.17510/wjhi.v9i1.222.

Qattan, Manna`. Mababith Fi `ulum Al-Qur'an. Bayrut: Mu’assasat al-Risalah, 2009.

R.E. Taylor. Radiocarbon Dating An Archaeological Perspective. Orlando: Acedemic Press, 1987.

Ricoeur, Paul. Interpretation Theory. Fort Worth: Texas Christian University Press, 1977. . "What Is a Text? Explanation and Understanding." In The Theory of Interpretation, edited and translated by John B. Thompson, 107-26. Cambridge: Cambridge University Press, 2016. https://doi.org/10.1017/cbo9781316534984.008.

Saputro, Muhammad Endy. "Mushaf 2.0 Dan Studi Al-Qur'an Di Era 'Muslim Tanpa Masjid." MIQOT: Jurnal Ilmu-Ilmu Keislaman, 2019. https://doi.org/10.30821/miqot.v42i2.502.

Suit, Natalia K. "Mushaf and The Material Boundaries of The Qur'ān.” In Iconic Books and Texts, edited by James Watts. Equinox Publishing, 2013.

Sumaryono, E. Hermeneutik: Sebuah Metode Filsafat. Yogyakarta: Kanisius, 1999.

Suryani, Elis. Filologi. Bogor: Ghalia Indonesia, 2012.

Teh Gallop, Annabel, and Ali Akbar. "The Art of the Qur'an in Banten: Calligraphy and Illumination." Archipel 72, no. 1 (2006): 95-156. https://doi.org/10.3406/arch.2006.4028.

Tim Peneliti balai Litbang Agama Jakarta. Naskab-Naskab Taubid Di Indonesia Bagian Barat. Jakarta: Balai Penelitian dan pengembangan Agama Jakarta, 2013.

White, Marilyn Domas, and Emily E. Marsh. "Content Analysis: A Flexible Methodology." Library Trends 55, no. 1 (2006): 22-45. https://doi.org/10.1353/lib.2006.0053. 